\title{
Improved Dimerization of Diethyl Acetonedicarboxylate Leading to Polyfunctionalized Phenol
}

\author{
Nagatoshi Nishiwaki* , Hajime YAgi, Takanobu Shinkawa, Makoto Matsumoto, \\ Mina Tamura and Masahiro Ariga \\ Department of Chemistry, Osaka Kyoiku University \\ (Asahigaoka 4-698-1, Kashiwara, Osaka 582-8582, JAPAN)
}

Edited by Y. Takizawa, Tokyo Gakugei Univ., and accepted April 4, 2005 (received for review December 24, 2004)

\begin{abstract}
When a pyridine solution of sodium enolate of diethyl acetonedicarboxylate was heated in the presence of $p$-nitrophenol, the dimerization readily proceeded under mild conditions to give polyfunctionalized phenol, ethyl $\{2,4$-bis(ethoxycarbonyl)-3,5dihydroxyphenyl acetate, in moderate yield.
\end{abstract}

Key words: dimerization, nitrophenol, dinitropyridone

\section{Introduction}

The condensation of binucleophilic and bielectrophilic reagents is one of the useful methodologies constructing various cyclic compounds. The ring transformation belongs to this category, which has been employed for elaborate syntheses of polyfunctionalized compounds (1-5). Highly electron-deficient cyclic compounds having a good leaving group in the ring are suitable substrates for this reaction, and are converted to new ring systems upon treatment with binucleophilic reagents. Diethyl acetonedicarboxylate (diethyl 3oxopentanedioate, 1) shows high synthetic utility, and reactions with several kinds of heterocyclic compounds caused ring transformations as illustrated in Scheme 1.

When diester 1 was allowed to react with nitroisoxazolone 2, pyrrole derivative $\mathbf{3}$ was prepared with loss of carbon dioxide (6). Easy elimination of anionic nitroacetamide enabled the effective conversion from nitropyrimidinone 4 to 3,5-bis(ethoxycarbonyl)-4-pyridone $5 \mathbf{a}(\mathrm{R}=\mathrm{H})$ and from 3,5-dinitro-2-pyridone $\mathbf{6}$ to functionalized nitrophenol 7 , respectively $(7,8) . \mathrm{N}$ -

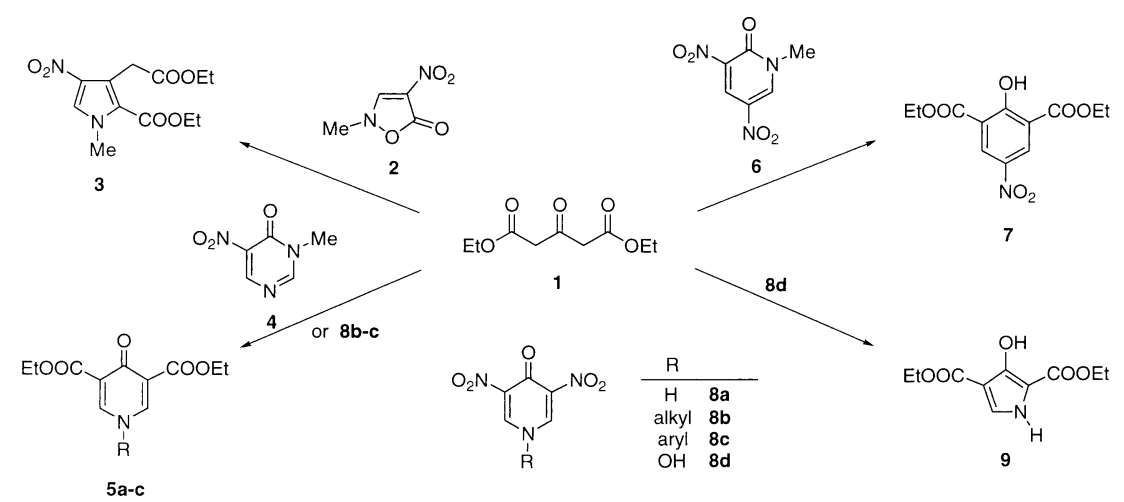

Scheme 1

\footnotetext{
* Correspondence to: Nagatoshi NiSHIWAKI, Department of Chemistry, Osaka Kyoiku University, Asahigaoka 4-698-1, Kashiwara, Osaka 5828582, JAPAN

E-mail: nishi@cc.osaka-kyoiku. ac.jp
} 
Substituted 3,5-dinitro-4-pyridones 8 were also usable as the substrate for the ring transformation. In cases of $\mathbf{8 b}(\mathrm{R}=$ alkyl $)$ and $8 \mathbf{c}(\mathrm{R}=$ aryl or hetaryl $)$, corresponding 3,5-difunctionalized 4-pyridones $\mathbf{5 b}$ and $\mathbf{5 c}$ were formed (9). On the other hand, unusual ring transformation proceeded to afford functionalized pyrrole 9 in the reaction of 1 with $N$-hydroxy-3,5-dinitropyridone $\mathbf{8 d}(\mathrm{R}=\mathrm{OH})$, whose acidic hydroxyl group is considered to be a key structure for the different behavior from $\mathbf{8 b}$ and $\mathbf{8 c}$ (10). On the basis of these results, we planned to study the ring transformation of 1 with $\mathrm{N}$ unsubstituted 3,5-dinitro-4-pyridone 8a $(\mathrm{R}=\mathrm{H})$, which might realize a new ring transformation.

\section{Experimental}

\section{General}

All the reagents and solvents were commercially available and used as received. ${ }^{1} \mathrm{H}$ NMR spectrum was measured on a Bruker DPX-400 at $400 \mathrm{MHz}$ with TMS as an internal standard.

\section{Typical Procedure}

To a solution of sodium hydroxide $(80 \mathrm{mg}, 2.0$ $\mathrm{mmol})$ in ethanol $(80 \mathrm{~mL})$, diethyl acetonedicarboxylate $1(0.36 \mathrm{~mL}, 2.0 \mathrm{mmol})$ was added, and the mixture was stirred at room temperature for 0.5 hour. After removal of ethanol under reduced pressure, the residual oil was dissolved into pyridine $(30 \mathrm{~mL})$, then was added a solution of $p$-nitrophenol 10a $(280 \mathrm{mg}, 2 \mathrm{mmol})$ in pyridine $(5 \mathrm{~mL})$. The solution was heated at $100^{\circ} \mathrm{C}$ for 5 hours, and the reaction was quenched with $1 \mathrm{M}$ hydrochloric acid $(2.5 \mathrm{~mL})$. After the solvent was evaporated, the residue was extracted with chloroform $(30 \mathrm{~mL} \times 3)$. The organic layer was dried over magnesium sulfate, and concentrated. Upon treatment of the residue with column chromatography on silica gel, polyfunctionalized phenol 11 was isolated as colorless needles (eluted with chloroform / ethyl acetate $=1 / 1,140 \mathrm{mg}, 0.41$ mmol, 41\%). ${ }^{1} \mathrm{H}$ NMR (400 MHz, $\left.\mathrm{CDCl}_{3}\right) \delta 1.24$ (t, $J=7.1 \mathrm{~Hz}, 3 \mathrm{H}), 1.37(\mathrm{t}, J=7.2 \mathrm{~Hz}, 3 \mathrm{H}), 1.45(\mathrm{t}, J=$ $7.1 \mathrm{~Hz}, 3 \mathrm{H}), 3.83$ (s, 2H), 4.14 (q, J=7.1 Hz, 2H), 4.36 $(\mathrm{q}, J=7.2 \mathrm{~Hz}, 2 \mathrm{H}), 4.49(\mathrm{q}, J=7.1 \mathrm{~Hz}, 2 \mathrm{H}), 6.36(\mathrm{~s}$, $1 \mathrm{H}), 11.98(\mathrm{~s}, 1 \mathrm{H}), 12.88(\mathrm{~s}, 1 \mathrm{H})$. Spectral data were identical to those of $\mathbf{1 1}$ (11).

When 8a was used as acid promoter instead of 10a, the reaction was performed in the same way.

\section{Results and Discussion}

When pyridone 8a was heated with sodium enolate of diester $\mathbf{1}$ at $100^{\circ} \mathrm{C}$ for 5 hours, more than $90 \%$ of $\mathbf{8 a}$ was recovered, however, polyfunctionalized phenol $\mathbf{1 1}$ was isolated in $31 \%$ yield. Since three ethoxy groups were unequivalently observed in both ${ }^{1} \mathrm{H}$ and ${ }^{13} \mathrm{C}$ NMR spectra, symmetrical structure $\mathbf{1 2}$ (Fig. 1) was denied as a plausible structure for the product of the present reaction. Descriptions of the product $\mathbf{1 1}$ are found in the literature (11-14), which is used as the synthetic intermediates for the biologically active compounds $(13,14)$. Although 11 could be prepared by the dimerization of diester $\mathbf{1}$ in the presence of metal ions such as $\mathrm{Cu}^{2+}$ and $\mathrm{Mg}^{2+}$ under severe conditions $(11,12)$, the reaction suffers from competitive decomposition of the product at the same time. In comparison with these known methods, the present pyridone assisting dimerization of $\mathbf{1}$ is more effective and requires milder reaction conditions. On the other hand, no reaction proceeded in the absence of $8 \mathbf{a}$.

The acidic protons of pyridone $\mathbf{8 a}$ surely promote the dimerization, however it was necessary to prepare 8a. This drawback was overcome by using commercially available $p$-nitrophenol 10a $(\mathrm{R}=\mathrm{H})$ instead of the pyridone (Table 1). Polyfunctionalized phenol 11 was obtained in $23 \%$ yield when a pyridine solution of sodium enolate of 1 was heated at $80^{\circ} \mathrm{C}$ in the presence of phenol 10a. The present dimerization was observed even at room temperature despite considerably slow reaction rate. When the reaction was conducted at $100^{\circ} \mathrm{C}$ for 1 hour, product 11 was formed in $14 \%$ yield with recovery of starting material, and the yield was improved up to $41 \%$ by heating for 5 hours. However, the reaction mixture was complicated in cases of overheating at higher temperature or for a long time. These experimental facts mean that the dimerization of $\mathbf{1}$ and<smiles>CCOC(=O)Cc1c(O)cc(O)c(C(=O)OCC)c1C(=O)OCC</smiles>

12

Fig. 1 
Table 1

\begin{tabular}{cccc} 
Additive & Temp. $/{ }^{\circ} \mathrm{C}$ & $\mathrm{Time} / \mathrm{h}$ & $\mathrm{Yield} / \%$ \\
\hline $\mathbf{8 a}$ & 100 & 5 & 31 \\
$\mathbf{1 0 a}$ & 80 & 5 & 23 \\
$\mathbf{1 0 a}$ & $\mathrm{rt}$ & 5 & 2 \\
$\mathbf{1 0 a}$ & 60 & 5 & 4 \\
$\mathbf{1 0 a}$ & 116 & 5 & 26 \\
$\mathbf{1 0 a}$ & 100 & 5 & 41 \\
$\mathbf{1 0 a}$ & 100 & 1 & 14 \\
$\mathbf{1 0 a}$ & 100 & 24 & $0^{a}$ \\
$\mathbf{1 0 b}$ & 100 & 5 & 7
\end{tabular}

${ }^{a}$ Complex mixture was obtained.

decomposition of $\mathbf{1 1}$ also proceeded competitively in this system.

When more acidic dinitrophenol $\mathbf{1 0 b}\left(\mathrm{R}=\mathrm{NO}_{2}\right)$ was used instead of $\mathbf{1 0 a}$, the yield of $\mathbf{1 1}$ was considerably lowered to $7 \%$, which suggested that the moderate acidic agent was necessary to promote the dimerization of 1. A plausible mechanism for this reaction is shown in Scheme 2. Since diester 1 and $p$-nitrophenol 10a have comparable $\mathrm{pKa}$ values, equilibrium between $\mathbf{1}$ and its enolate is accelerated, which realizes the presence of both reagents and their conjugate bases in the same reaction mixture. As another role, nitrophenol
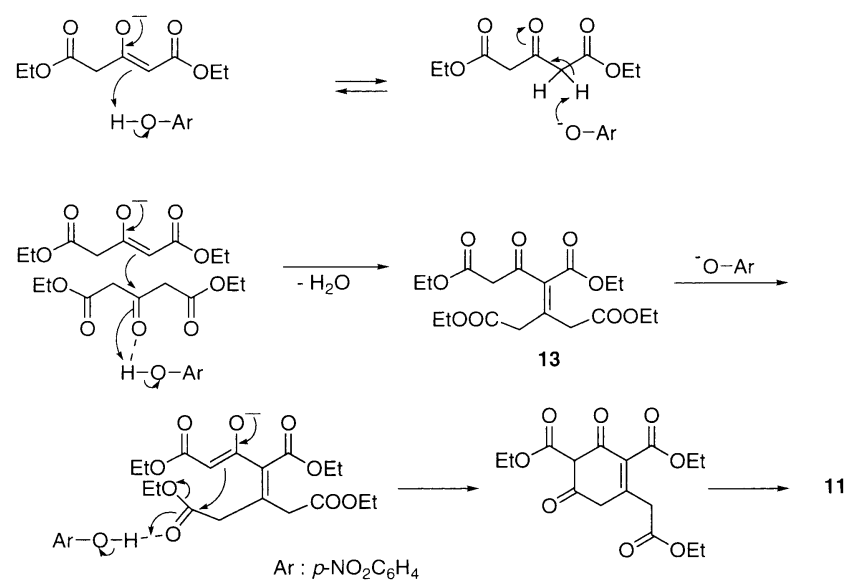

Scheme 2 10a activates the carbonyl group of $\mathbf{1}$ to facilitate the condensation with its enolate leading to give polysubstituted alkene 13. The intramolecular nucleophilic substitution followed by aromatization furnishes phenol 11.

In summary, polyfunctionalized phenol 11 was prepared by condensation of commercially available reagents with simple experimental manipulations. This reaction is concluded to be an improved method for the dimerization of diethyl acetonedicarboxylate $\mathbf{1}$.

\section{References}

1. S.P. GROMOV, Ring Transformation of Pyridines and Benzo Derivatives under the Action of $C$-Nucleophiles, Heterocycles, Vol. 53, 1607-1630 (2000).

2. H.C. VAN DER PLAS, Degenerate Ring Transformation of Heterocyclic Compounds, Adv. Heterocycl. Chem., Vol. 74, Academic Press, London (1999).

3. K. TAKAGI and M. HUBET-HABART, Ring Transformation of 5-Acylpyrimidines and 5-Acyluracils into Pyrazoles with Hydrazines in Acidic Medium, J. Heterocycl. Chem., Vol. 33, 1003-1015 (1996).

4. V.L. RUSINOV, O.N. CHUPAKHIN and H.C. VAN DER PLAS, Transformations of Nitropyrimidines by Action of $C$-Nucleophiles, Heterocycles, Vol. 40, 441-475 (1995).

5. H.C. VAN DER PLAS, Ring Transformations of Heterocycles, Vol. 1-2, Academic Press, London (1973).

6. N. NISHIWAKI, M. NAKANISHI, T. HIDA, Y. MIWA, M. TAMURA, K. HORI, Y. TOHDA and M. ARIGA, Synthesis of 2,3-Difunctionalized 4-Nitropyrroles, J. Org. Chem., Vol. 66, 7535-7538 (2001).

7. N. NISHIWAKI, Y. TOHDA and M. ARIGA, Nitropyrimidinones; Synthetic Equivalents of Diformylamine and Nitromalonaldehyde, Synthesis, 1277-1280 (1997).

8. E. MATSUMURA, M. ARIGA and Y. TOHDA, Nucleophilic Reaction of Electron-Deficient Pyridone Derivatives. I. The Ring Transformation of 1-Substituted 3,5-Dinitro-2-pyridones with Sodio $\beta$-Keto Esters, Bull. Chem. Soc. Jpn., Vol. 52, $2413-$ 2419 (1979).

9. E. MATSUMURA, M. ARIGA and Y. TOHDA, Nucleophilic Reaction of Electron-Deficient Pyridone Derivatives. II. Ring Transformation of 1-Substituted 3,5-Dinitro-4-pyridones with Sodio $\beta$-Keto Esters, Bull. Chem. Soc. Jpn., Vol. 53, 2891-2894 (1980).

10. N. NISHIWAKI, K. MATSUSHIMA, M. TAMURA, N. ASAKA, K. HORI, Y. TOHDA and M. ARIGA, Unusual Ring Transformation of $\mathrm{N}$-Hydroxy-3,5-dinitro-4-pyridone Affording Polyfunctionalized Pyrrole, Arkivoc, Vol. x, 34-39 (2002).

11. M. YAMATO, J.-i. UENISHI and K. HASHIGAKI, Condensation of Diethyl Acetonedicarboxylate. II, Chem. Pharm. Bull., Vol. 26, 1973-1980 (1978). 


\section{N. Nishiwaki, H. Yagi, T. Shinkawa et al.}

12. M. YAMATO and Y. KUSUNOKI, Condensation of Diethyl Acetonedicarboxylate. III. Isolation and Acylation of Diethyl Acetonedicarboxylate-Magnesium Complex, Chem. Pharm. Bull., Vol. 29, 1214-1220 (1981).

13. M. YAMATO and K. HASHIGAKI, Synthesis of $d l$-Agrimono- lide (Constituent of Rhizome of Agrimonia pilosa Ledeb), Chem. Pharm. Bull., Vol. 24, 200-203 (1976).

14. F. VIVIANI, M. GAUDRY and A. MARQUET, Melanin Biosynthesis: A Study of Polyphenol Deoxygenation, J. Chem. Soc., Perkin Trans. 1, 1255-1259 (1990). 